\title{
Long-Term Effectiveness and Safety of Childhood Growth Hormone Treatment in Noonan Syndrome
}

\author{
Tilman R. Rohrer $^{\mathrm{a}} \quad$ Jennifer Abuzzahab ${ }^{\mathrm{b}} \quad$ Philippe Backeljauw ${ }^{\mathrm{c}}$
}

Anna Camilla Birkegård ${ }^{d}$ Joanne Blair ${ }^{\mathrm{e}}$ Jovanna Dahlgren ${ }^{f}$

Pétur Benedikt Júlíusson ${ }^{g, h, i}$ Vlady Ostrow ${ }^{j}$ Alberto Pietropolik ${ }^{k}$ Michel Polak ${ }^{\prime}$

Alicia Romano $^{m}$ Judith Ross ${ }^{n}$ Lars Sävendahlo ${ }^{\circ}$ Bradley S. Miller ${ }^{p}$

\begin{abstract}
aDepartment of Pediatric Endocrinology, University Children's Hospital, Saarland University Medical Center,

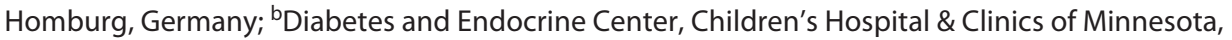

Saint Paul, MN, USA; 'Cincinnati Children's Hospital Medical Center, University of Cincinnati College of Medicine, Cincinnati, OH, USA; ' ${ }^{E}$ pidemiology, Novo Nordisk A/S, Søborg, Denmark; 'Department of Paediatric Endocrinology, Alder Hey Children's NHS Foundation Trust, Liverpool, UK; fDepartment of Paediatrics, Region Västra Götaland, Sahlgrenska University Hospital, Gothenburg, Sweden; 9Department of Paediatrics, Haukeland University Hospital, Bergen, Norway; hepartment of Health Registry Research and Development, National Institute of Public Health, Bergen, Norway; 'Department of Clinical Science, University of Bergen, Bergen, Norway; 'Medical Affairs, Novo Nordisk Inc., Princeton, NJ, USA; ${ }^{k}$ Global Medical Affairs, Novo Nordisk Health Care AG, Zurich, Switzerland; IPaediatric Endocrinology, Diabetology and Gynaecology Department, Necker Children's University Hospital, Imagine Institute, Paris, France; 'm Department of Pediatrics, New York Medical College, Valhalla, NY, USA; ${ }^{n}$ Nemours DuPont Hospital for Children and Department of Pediatrics, Thomas Jefferson University, Philadelphia, PA, USA; ${ }^{\circ}$ Pediatric Endocrinology, Karolinska University Hospital and Department of Women's and Children's Health, Karolinska Institutet, Solna, Sweden; PPediatric Endocrinology, University of Minnesota Masonic Children's Hospital, Minneapolis, MN, USA
\end{abstract}

\section{Keywords \\ Noonan syndrome - Growth hormone therapy • Effectiveness - Safety · Near-adult height · RASopathy · Puberty · Real-world evidence · Adolescent . Ras/mitogen-activated protein kinase}

\begin{abstract}
Introduction: Few data exist on long-term growth hormone (GH) treatment in patients with Noonan syndrome (NS). Objective: To evaluate the effectiveness and safety of GH treatment in NS in clinical practice. Methods: Height gain, nearadult height (NAH), and safety were assessed in 2 comple-
\end{abstract}

mentary non-interventional studies: NordiNet ${ }^{\circledR}$ IOS and ANSWER. The safety analysis included 412 patients, and the effectiveness analysis included $84 \mathrm{GH}$-treated patients (male, $n=67$ ) with $\geq 4$ years' height standard deviation score (HSDS) data. HSDS was determined using national reference (NR) and NS-specific (NSS) data. Results: The mean (SD) baseline age was 8.38 (3.57) years; HSDS, -2.76 (1.03); GH dose, 41.6 (11.1) $\mu \mathrm{g} / \mathrm{kg} /$ day. The mean (SD) HSDS increase from baseline ( $\triangle \mathrm{HSDS}$ ) was 0.49 (0.37) (first year), 0.79 (0.58) (second year), and $1.01(0.60)$ (third year) (NR). The mean (SD) HSDS at year 3 was -1.66 (1.00) (NR; 1.06 [1.12] [NSS]). Twenty-four patients achieved NAH. The mean (SD) NAH SDS (NR) was $-1.51(0.60)(154.90[3.21] \mathrm{cm})$ in females and -1.79 (1.09) karger@karger.com www.karger.com/hrp

Karger $\stackrel{\text { ' }}{5}$

BOPEN ACCESS
(C) 2021 The Author(s)

Published by S. Karger AG, Basel

This is an Open Access article licensed under the Creative Commons Attribution-NonCommercial-4.0 International License (CC BY-NC) (http://www.karger.com/Services/OpenAccessLicense), applicable to the online version of the article only. Usage and distribution for commercial purposes requires written permission.
Tilman R. Rohrer

Department of Pediatric Endocrinology, University Children's Hospital Saarland University Medical Centre

Kirrberger Strasse, DE-66421 Homburg/Saar (Germany) tilman.rohrer@uks.eu 
$(165.61[7.19] \mathrm{cm})$ in males; $70.8 \%(17 / 24)$ had NAH SDS $\geq-2$. Adverse drug reactions and GH-unrelated serious adverse events $(n=34)$ were reported in 22/412 (5.3\%) patients. Four neoplasms and 3 cases of scoliosis were reported; no cardiovascular adverse events occurred. Conclusions: $\mathrm{GH}$-treated children with NS achieved substantial height gain during the first 3 years of follow-up. Overall, 24 patients achieved $\mathrm{NAH}$, with $70.8 \%$ having NAH SDS $\geq-2$. There was no evidence to support a higher prevalence of neoplasm, or cardiac or other comorbidities.

(C) 2021 The Author(s)

Published by S. Karger AG, Basel

\section{Introduction}

Noonan syndrome (NS) is a common genetic multisystem condition that was characterized by Noonan and Ehmke in 1963 [1]. It comprises a series of clinical features, including short stature, a characteristic facial appearance, congenital heart disease, and skeletal anomalies. NS is caused by mutations affecting the Ras/mitogenactivated protein kinase (MAPK) cascade $[2,3]$. In most cases, the genetic mutations causing NS are 'gain of function' mutations that result in hyperactivation of Ras/ MAPK, which may be responsible for the NS phenotype, including short stature [4].

In addition to the key features of congenital heart disease, skeletal anomalies, short stature, and a characteristic facial appearance, NS is associated with a multitude of other comorbidities. Many cardiovascular phenotypes can occur in NS, most commonly pulmonary stenosis, hypertrophic cardiomyopathy, and atrial septal defects, but ventricular septal defect, aortic stenosis, aortic aneurysm, and other anomalies have also been described [5, 6]. Skeletal features include chest wall deformities of pectus carinatum and excavatum, as well as scoliosis [7]. Short stature is common, although birth weight and birth length are usually normal. A delayed or attenuated growth spurt results in pre-existing short stature becoming more noticeable during the age of normal puberty [6]. Unilateral or bilateral cryptorchidism is diagnosed in up to $80 \%$ of boys diagnosed with NS [6]. Other comorbidities include feeding difficulties, lymphatic abnormalities, auditory deficits, multiple giant cell lesions, and cerebrovascular anomalies [6]. A number of haematological cancers, such as juvenile myelomonocytic leukaemia, have been reported in individuals with NS [8], and risk of tumour development has been estimated as 3.5-8.1 times higher than in the general population $[8,9]$.

Effectiveness and Safety of Growth

Hormone in Noonan Syndrome
In 2007, growth hormone (GH) received US FDA approval to treat short stature in patients with NS in the USA. It is also approved in Brazil, Israel, Japan, South Korea, and Switzerland. To date, most of the experience with GH in patients with NS has been accrued from retrospective case studies and observational studies. Shortterm studies have demonstrated improvements in height velocity and increases in mean height standard deviation score (HSDS) [10-14], supporting the short-term use of GH in patients with NS for managing short stature. However, 9 studies have reported adult or nearadult height (NAH) outcomes in patients with NS treated with GH [15-23]. Many of these studies involved small numbers of patients and variations in duration of treatment, age at start of treatment, and definitions of NAH. For those studies of patients with NS who achieved adult or NAH after at least 5 years of GH with doses at or above $0.3 \mathrm{mg} / \mathrm{kg} /$ week, based on national growth references, the change in HSDS ranged from 1.3 to 1.7 [17, $18,20,22,23]$. A recent randomized, double-blind, multi-centre trial investigating the effect of dose on the growth-promoting effect of $\mathrm{GH}$ in pre-pubertal children with NS demonstrated a significant improvement in height gain with a dose of 66 versus $33 \mu \mathrm{g} / \mathrm{kg} /$ day [24]. In addition to dose, other factors associated with improved outcome include earlier initiation of GH therapy and longer pre-pubertal duration of therapy [17, 20,23]. Long-term data on the effect of GH treatment on height outcomes in clinical practice in a large cohort of patients are sparse.

The accumulated safety data on GH treatment in NS are reassuring [20] and include no evidence of adverse cardiac effects $[11,25]$ or increased occurrence of malignancies $[17,20,26]$. There is, however, a paucity of data on the long-term safety of GH therapy in patients with NS, especially regarding the risk of tumour development and tumour recurrence. Considering the inherent risk for the development of malignancies in NS patients, it is pertinent that there are only 4 published clinical reports of brain tumours being diagnosed in patients with NS treated with GH [26]. Although there does not appear to be an increased risk for the development or progression of scoliosis or hypertrophic obstructive cardiomyopathy in individuals with NS treated with GH $[11,20,22]$, it has not been systematically studied. Thus, continued surveillance is necessary.

The aim of this study was to provide further insight into the effectiveness of long-term GH therapy up to $\mathrm{NAH}$, as well as the safety of long-term GH treatment in patients with NS, using pooled data from 2 complemen-

Horm Res Paediatr 2020;93:380-395 381 
tary, multi-national, non-interventional studies: Nordi$\mathrm{Net}^{\circledR}$ International Outcome Study (IOS) and the American Norditropin ${ }^{\circledR}$ Studies: Web-Enabled Research (ANSWER) Program ${ }^{\circledR}$. These studies have collected data from real-world clinical practice over a 10 -year follow-up period on a large $(n=412)$ cohort of GH-treated patients with NS. In this report, we present data on patients with NS with $>4$ years of follow-up. A report on the effectiveness and safety of up to 4 years of GH treatment in children with NS enrolled in NordiNet ${ }^{\circledR}$ IOS and ANSWER has previously been published $[14,27]$.

\section{Materials and Methods}

\section{Study Design}

The study designs of NordiNet $^{\circledR}$ IOS (ClinicalTrials.gov NCT00960128) and ANSWER (ClinicalTrials.gov NCT00615953) are described in detail elsewhere [28]. In brief, NordiNet ${ }^{\circledR}$ IOS (April 2006-December 2016) was a multi-centre, longitudinal, observational cohort study conducted in 23 countries, mostly in Europe (non-European countries were Russian Federation and Saudi Arabia), based on the systematic collection of data in patients treated with GH (Norditropin ${ }^{\circledR}$ [somatropin], Novo Nordisk A/S). ANSWER (June 2002-September 2016) was originally a post-marketing registry of adults and paediatric patients in the USA treated with Norditropin ${ }^{\circledR}$ and was developed into a non-interventional, observational study.

In both studies, GH was administered as directed by the treating physician and according to routine practice and local regulations. Approval was obtained from relevant ethics committees, written informed consent was obtained, and all data were anonymized. The studies were conducted in accordance with the Declaration of Helsinki, Guideline for Good Pharmacoepidemiology Practices, and regulatory requirements.

The 2 studies were complementary, with similar aims, using the same electronic platform for data management. Data capture was through electronic case report forms using web-based platforms $\left(\right.$ NordiNet $^{\circledR}$ and NovoNet ${ }^{\circledR}$ ), with automatic validation at data entry. Because of the similarities in study design and data capture, the results of the 2 studies could be pooled for the cohort of patients with NS who were treated with GH.

The safety analysis set included all patients who received at least 1 dose of GH. The total effectiveness analysis set (EAS) consisted of all patients in the safety analysis set who were naïve to $\mathrm{GH}$ at treatment start and who had data on HSDS. The EAS reported in this study included all patients in the total EAS with $\geq 4$ years of data on HSDS. The NAH analysis set included all patients who had achieved NAH in the safety analysis set.

\section{Patients}

Eligible study participants were paediatric patients with a clinical diagnosis of NS enrolled in NordiNet ${ }^{\circledR}$ IOS or ANSWER in whom treatment with Norditropin ${ }^{\circledR}$ was initiated before 18 years of age. Diagnosis of NS was determined by the participating physicians. There was no requirement for genetic testing of patients with NS for inclusion in either study, although genetic data were collected for some patients in ANSWER. The EAS comprised patients with $>4$ years of follow-up data. All patients and/or their parents or caregivers gave written informed consent prior to study enrolment and could withdraw from the study at any time.

\section{Data Extraction and Statistical Analyses}

Data were collected according to routine clinical practice [28]. Baseline data were collected within a 6-month window before $\mathrm{GH}$ treatment started. Follow-up data were collected at annual clinic visits ( \pm 3 months). In both studies, numerous effectiveness endpoints were assessed [28], with change from baseline in HSDS a key effectiveness outcome. The main demographic and clinical characteristics reported at study visits included birthdate, sex and clinical diagnosis, patient's height, parents' height, bone age, age at GH treatment initiation, GH dose, and serum IGF-I concentrations [28]. Pubertal status (pre-pubertal defined as Tanner breast stage $\mathrm{B} 1$; testicular volume $<4 \mathrm{~mL}$ ) was gathered where reported.

Safety data were based on physicians' reporting of adverse events (AEs) and included adverse reactions (ARs; AEs deemed related to product), classed as serious (SARs) or non-serious (NSARs), and serious adverse events (SAEs) not related to GH. In NordiNet ${ }^{\circledR}$ IOS, SAEs were recorded throughout the study and were included in the present analyses. In ANSWER, it was not mandatory to report SAEs until November 9, 2011, when the protocol was amended; therefore, only SAEs reported after this date were included in the present analysis. It is likely that there was a certain degree of under-reporting of safety data collected during the studies as well as data on comorbidities at baseline from both studies due to the observational design of both studies. In both studies, a double assessment of causality was used to identify any causal relationship to GH therapy for AEs that were reported during the study. Thus, causality of each event was assessed by both the treating physician as well as by the study sponsor. If either the treatment physician or the study sponsor considered the relationship between an event and GH treatment as either probable or possible, the event was classed as an SAR (if judged serious) or an NSAR (if non-serious). Events that were considered unlikely to be related to $\mathrm{GH}$ treatment were reported as an SAE. Monitoring specific health concerns in patients with NS during GH treatment (e.g., blood pressure measurements, performing echocardiography, spinal examinations, and X-ray studies) was performed according to the individual treating clinician's discretion. This was not specified in the study protocol.

Mean GH dose by treatment year was calculated as the mean of the mean daily GH dose per patient. IGF-I values were measured locally and converted into IGF-I SDS based on age- and sex-related normative reference values [29]. The growth response (HSDS) from baseline to up to 10 years of follow-up was compared with national reference growth charts and disease-specific reference charts [30]. The gap to genetic height potential, that is, targetheight (TH)-corrected HSDS during the follow-up period, was defined as HSDS minus target HSDS. TH was determined using the corrected mid-parental height method (adding/subtracting $6.5 \mathrm{~cm}$ for boys/girls, respectively) [31].

Changes in HSDS ( $\triangle$ HSDS) from baseline were calculated, and the growth response in children with NS was analyzed and compared by a mixed linear model including repeated measures [14]. This was performed for 3 different responses: $\triangle$ HSDS based on national references, $\triangle H$ SDS based on NS-specific references [30], and $\triangle$ HSDS based on TH-corrected HSDS. To adjust for confounding factors, the data model included covariates of age at 
Table 1. Baseline demographic characteristics of patients with Noonan syndrome included in the EAS

\begin{tabular}{|c|c|c|c|c|c|c|}
\hline Characteristic & \multicolumn{2}{|c|}{ All $(N=84)$} & \multicolumn{2}{|c|}{$<7$ years $(n=63)$} & \multicolumn{2}{|c|}{$\geq 7$ years $(n=21)$} \\
\hline Gender (M:F), $n(\%)$ & $67: 17$ & $80 \%: 20 \%$ & $53: 10$ & $84 \%: 16 \%$ & $14: 7$ & $67 \%: 33 \%$ \\
\hline Age (range) at GH start, years & 84 & $\begin{array}{l}8.38(3.57) \\
{[2.32-15.72]}\end{array}$ & 63 & $\begin{array}{l}9.00(3.55) \\
{[2.48-15.72]}\end{array}$ & 21 & $\begin{array}{l}6.50(2.95) \\
{[2.32-11.39]}\end{array}$ \\
\hline HSDS (Ranke) [30] & 84 & $-0.31(1.04)$ & 63 & $-0.18(1.01)$ & 19 & $-0.71(1.08)$ \\
\hline TH SDS & 61 & $-0.51(1.01)$ & 48 & $-0.43(1.04)$ & 13 & $-0.77(0.83)$ \\
\hline TH-corrected SDS ${ }^{\mathrm{b}}$ & 61 & $-2.13(2.25)$ & 48 & $-2.20(1.16)$ & 13 & $-2.34(1.58)$ \\
\hline Bone age, years & 33 & $7.00(3.26)$ & 28 & $7.45(3.27)$ & 5 & $4.50(1.97)$ \\
\hline Bone age/chronological age & 33 & $0.80(0.15)$ & 28 & $0.82(0.14)$ & 5 & $0.66(0.14)$ \\
\hline IGF-I SDS & 21 & $-1.28(1.91)$ & 17 & $-1.45(2.02)$ & 4 & $-0.56(1.30)$ \\
\hline
\end{tabular}

In total, 84/412 patients with NS enrolled in NordiNet ${ }^{\circledR}$ IOS and ANSWER were included in the EAS. Baseline data were collected within a 6-month window before GH treatment started. EAS, effectiveness analysis set; GH, growth hormone; IGF-I, insulin like growth factor I; HSDS, height standard deviation score; SDS, standard deviation score; TH, target height. ${ }^{a}$ Unless otherwise stated. ${ }^{\mathrm{b}}$ TH-corrected HSDS refers to attainment of genetic height potential, that is, parental-height-corrected HSDS, defined as HSDS minus TH SDS, during 4 years of $\mathrm{GH}$ treatment.

treatment start, HSDS at baseline, and average GH dose. Estimates adjusted for confounders are denoted "adjusted." The figures show mean estimated values obtained by mixed linear models including repeated measures and adjusted for confounders. A decrease in growth was observed around year 7 of follow-up. To examine this further, HSDS data were analyzed for patients in the EAS $(n=84)$ with $<7$ years' growth data compared to those with $\geq 7$ years' growth data. The growth data were also separated into data collected before and after puberty to avoid the noise that puberty would have added to the data when analyzing the height SDS data by years of exposure. Puberty was defined as Tanner breast stage $\geq 2$ in girls and testicular volume $\geq 4 \mathrm{~mL}$ in boys [27]. NAH was defined as the height achieved when the height velocity was $<2 \mathrm{~cm} /$ year and chronological age was $>16$ years for boys and $>15$ years for girls, or when chronological age was $>18$ years. Individual data on all patients included in the effectiveness analyses were also screened to ensure that all patients whose growth had slowed to $<2 \mathrm{~cm} /$ year were included in the analyses of NAH (determined as mean [SD] and median and range). Estimated values (mean \pm SE) obtained by mixed linear models including repeated measures and adjusted for confounders are presented.

\section{Results}

\section{Baseline Characteristics}

Table 1 details the 412 patients with NS who were enrolled in NordiNet ${ }^{\circledR}$ IOS and ANSWER (NordiNet ${ }^{\circledR}$ IOS, $n=154$; ANSWER, $n=258$ ), received at least 1 dose of
$\mathrm{GH}$, and were included in the safety analysis set. From the 412 patients in the safety analysis set (of whom 292 [70.9\%] were male), $266(64.6 \%)$ patients (NordiNet ${ }^{\circledR}$ IOS, $n=106$; ANSWER, $n=160)$ were included in the total EAS. Of these, 84 patients $(20.4 \%$ of the safety analysis set; NordiNet ${ }^{\circledR}$ IOS, $n=41$; ANSWER, $n=43$ ) had $\geq 4$ years of data on HSDS and formed the EAS reported in this publication. Details of these populations and reasons for exclusion from the analysis sets are shown in Figure 1.

Details of comorbidities at baseline that were reported in 3 or more patients with NS are shown in online suppl. Table 2 (see www.karger.com/doi/10.1159/000512429 for all online suppl. material). Multiple comorbidities were reported by $151 / 412$ patients. In total, 41 patients had cardiovascular comorbidities, with 9 having multiple cardiovascular comorbidities. Congenital cardiovascular comorbidities reported at baseline included congenital pulmonary stenosis (6 cases) and congenital malformation of the heart ( 3 cases). Two patients had coarctation of the aorta at baseline. Neoplasms were reported in 2 patients at baseline (supratentorial neoplasm, benign, $n=1$; malignant neoplasm, unspecified, $n=1$ ), and 8 patients had musculoskeletal comorbidities, including 1 case of scoliosis. Cryptorchidism was reported in 5 patients (undescended testicle, unilateral, $n=3$; undescend- 


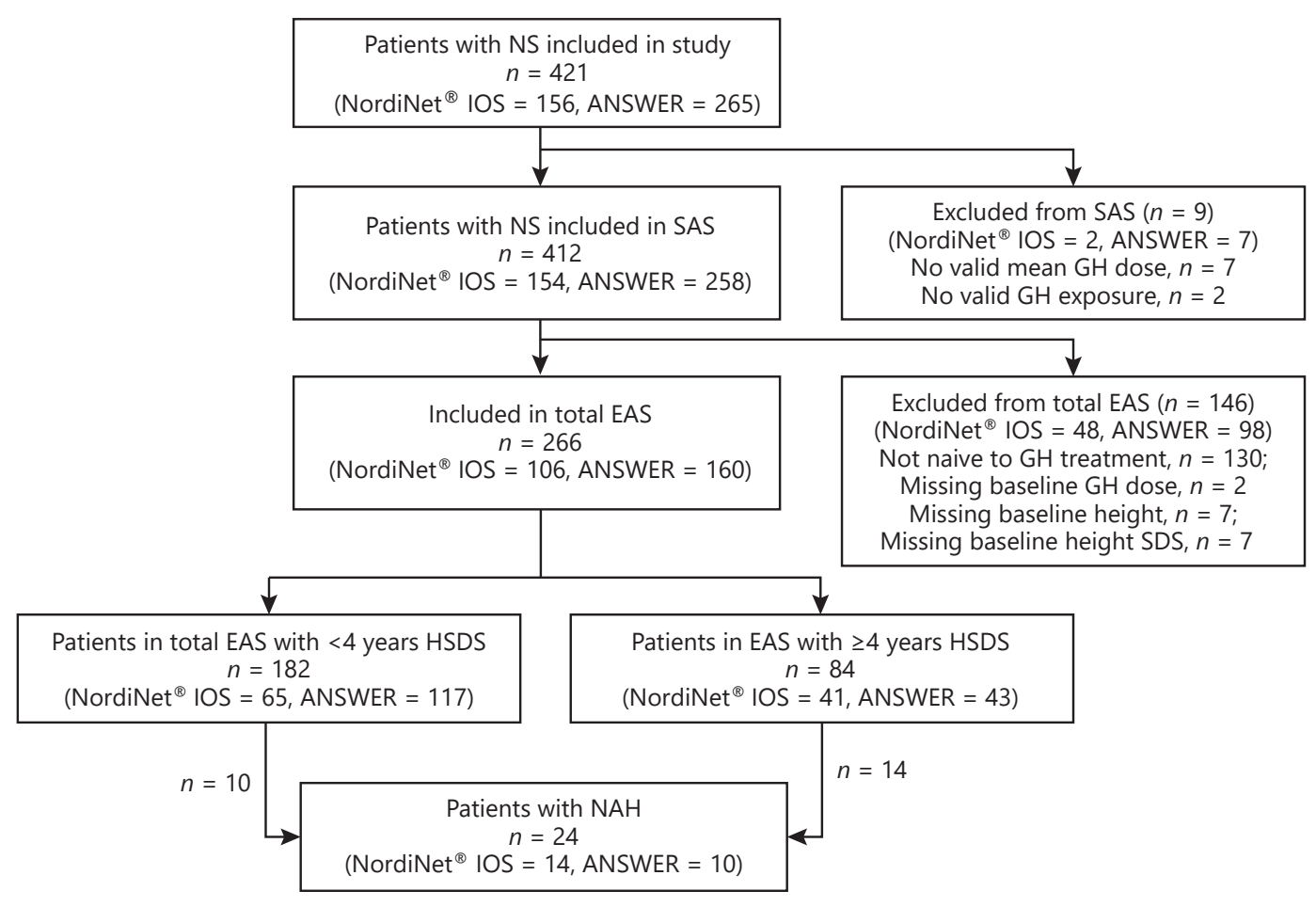

Fig. 1. Flow diagram of the total number of patients with NS enrolled in NordiNet ${ }^{\circledR}$ IOS and ANSWER. Subsets comprise the number of patients included in the SAS, total EAS, and the EAS with $<4$ and $\geq 4$ years of data on HSDS. The SAS includes all patients with available birthdate information who were $<18$ years of age and with at least 1 Norditropin ${ }^{\circledR}$ prescription recorded. The EAS includes all patients included in the SAS with $>4$ years of follow-up data. EAS, effectiveness analysis set; HSDS, height standard deviation score; NS, Noonan syndrome; SAS, safety analysis set; NAH, near-adult height. ed testicle, bilateral, $n=2$ ). Because of the observational design of the NordiNet ${ }^{\circledR}$ IOS and ANSWER studies, it is likely that comprehensive reporting of all comorbidities was not achieved and that there was an under-reporting of comorbid conditions at baseline.

Baseline characteristics for the 84 patients with $\geq 4$ years of HSDS data available are presented in Table 1 : $80 \%$ were male, the mean observed baseline HSDS was -2.76 (1.03) based on national growth references and -0.30 (1.04) using an untreated NS-specific reference population (Ranke) [30]. At baseline, 69 (82\%) patients were pre-pubertal (mean [SD] age, 7.7 [3.4] years) and 9 were pubertal (mean age, 12.6 [1.7] years) (data missing for 3 patients).

\section{Genetic Diagnoses}

Information on genetic mutation testing was available for 63/412 (15.3\%) patients in the safety analysis set who were enrolled in ANSWER, of whom 61 patients had a confirmed mutation as follows: PTPN11 $(n=56)$, KRAS $(n=2), \operatorname{SOS} 1(n=2), \operatorname{RAF} 1(n=5)$, and SHOC2 $(n=1)$. Three patients had $>1$ mutation: 1 had mutations in PTNP11 and SOS1; 1 had KRAS, PTPN11, SOS1, and RAF1 mutations; and 1 patient had PTPN11 and RAF1 mutations. Four of the patients with genetic mutation testing data were included in the EAS: PTPN11 $(n=3)$, $R A F(n=2)$, and SOS1 $(n=2)$, with 2 patients having both $P T P N 11$ and RAF1 mutations.

\section{Growth Hormone Dose}

For patients in the EAS, the mean (SD) GH dose at baseline was $41.6(11.1) \mu \mathrm{g} / \mathrm{kg} /$ day. There was a statistically significant increase in mean cumulative daily dose from year 1 (42.7 [9.8] $\mu \mathrm{g} / \mathrm{kg} /$ day) to year 3 (46.3 [11.0] $\mu \mathrm{g} / \mathrm{kg} /$ day) $(p=0.0282)$. After year 3 , the mean dose remained above baseline, fluctuating between a minimum of $44.2 \mu \mathrm{g} / \mathrm{kg} /$ day in year 5 and a maximum of $49.5 \mu \mathrm{g} / \mathrm{kg} /$ day in year 10 . Small numbers of patients in 


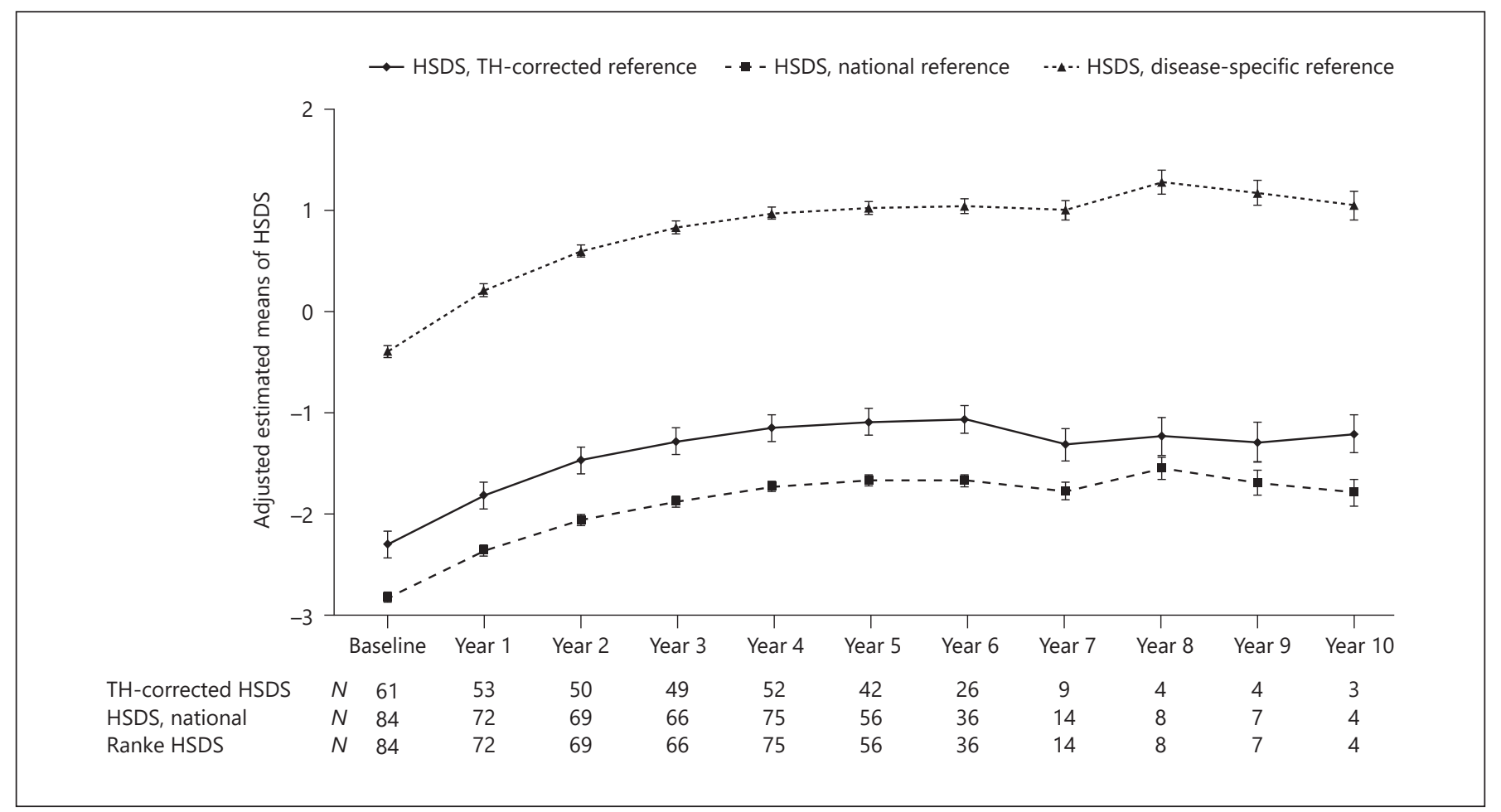

Fig. 2. Comparison of the adjusted estimated means of HSDS references for NS. Response to treatment with GH in 84 patients with NS, in whom $\geq 4$ years' growth data were available, is expressed as HSDS for normal, TH-corrected, and disease-specific (Ranke [30]) reference data. The estimated mean changes in these HSDS refer-

years 8,9 , and 10 made interpretation of trends in these data more difficult. The mean ([SD]; P10, P90) duration of GH treatment was 5.7 ([2.2]; 3.9, 8.4) years.

\section{Effectiveness}

Growth Response according to National and DiseaseSpecific Reference Growth Charts and Target-Height Adjusted Data

There was an increase in HSDS from baseline during the follow-up period (Fig. 2) [30]. HSDS values based on national references were lower than $\mathrm{TH}$-corrected HSDS (based on national references) values (Fig. 2) (see online suppl. Table 1 for unadjusted estimated means for HSDS). Based on national references, the baseline HSDS (mean [SD]) was -2.76 (1.03), increasing to -1.66 (1.00) by year 3 . Thus, after 3 years of GH therapy, HSDS (based on national references) had increased from below the normal range at baseline to within the normal range ( -2 to 2$)$. From years 5-6 and beyond, there was a plateau or decrease in HSDS (based on national references), with little or no further gain in HSDS.

Effectiveness and Safety of Growth Hormone in Noonan Syndrome

ences $( \pm$ SE) for NS were compared. Adjusted estimated means $( \pm$ SE) of HSDS by year of follow-up, adjusted for age at treatment start, HSDS at baseline, and average GH dose. GH, growth hormone; HSDS, height standard deviation score; NS, Noonan syndrome; SE, standard error; $\mathrm{TH}$, target height.

Using the Ranke (NS-specific) reference [30], the baseline HSDS was -0.30 (1.04), increasing to 1.06 (1.12) after 3 years. The disease-specific Ranke $\Delta$ HSDS (SD) was 0.64 $(0.31)$ at year 1 , increasing to $1.29(0.60)$ at year 3 and 1.46 $(0.81)$ at year 5 . At baseline (based on NS-specific reference), $20 \%(n=17 / 84)$ of patients had HSDS $>-2$. At year 1 , this proportion had increased to $52 \%(n=42 / 81)$ and, at years $2(61 \%, n=48 / 79)$ and $3(80 \%, n=63 / 79)$, this proportion was further increased. In subsequent years of follow-up (years 4-6), the proportion of patients with HSDS $>-2$ remained $\geq 70 \%$. At 10 years of followup $(n=4)$, the mean (SD) HSDS for patients treated with GH was -0.68 (1.04) (Ranke reference [30]).

TH-corrected $\triangle$ HSDS (national references) and $\triangle$ HSDS (national references) were very similar (Fig. 3). As shown in Figure 3, there was an increase in $\triangle \mathrm{HSDS}$ (national references) up to years 5-6. The $\triangle$ HSDS (mean [SD]) was $0.49(0.37)$ at year 1 increasing to $1.01(0.60)$ at year 3 and $1.17(0.69)$ at year 5 . The modelling analysis indicated that $\triangle$ HSDS (national references) was higher with lower baseline age $(p=0.0142)$ and higher HSDS at 


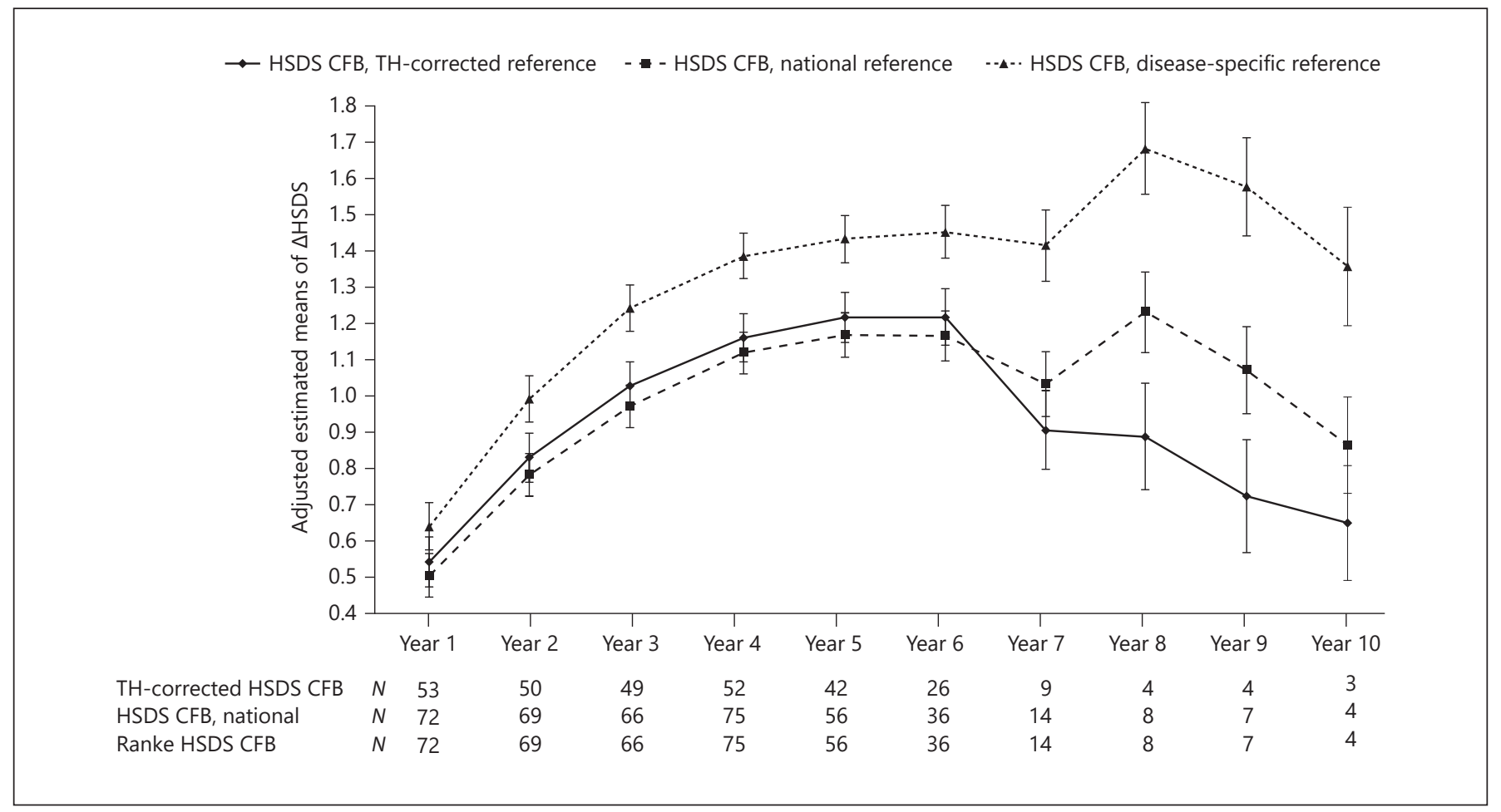

Fig. 3. Comparison of the adjusted estimated mean changes from baseline of HSDS references for NS. HSDS was adjusted for normal, TH-corrected, and disease-specific (Ranke [30]) reference data. The estimated mean changes from baseline of these HSDS references $( \pm \mathrm{SE})$ for NS were compared. Adjusted estimated

baseline $(p<0.0001)$ indicating a better growth response in patients who were younger and/or taller at baseline.

There appeared to be a different growth response after 7 years of follow-up in comparison to that observed during the first 6 years of follow-up (Fig. 2, 3). We therefore analyzed the growth response in terms of HSDS for the sub-cohorts of patients with $<7$ years of follow-up and $\geq 7$ years of follow-up and by pubertal status.

\section{Growth Response - by Duration of Follow-Up ( $<7$ vs. $\geq 7$ years)}

Baseline characteristics for patients by length of follow-up $(<7 / \geq 7$ years $)$ showed that there was a similar distribution of male and female patients as in the total cohort (Table 1). However, the patients with $\geq 7$ years of followup were younger at treatment start than those with $<7$ years of follow-up and had a lower HSDS (national references and NS disease-specific references) and lower target HSDS (national references) at baseline than those with $<7$ years of follow-up. Mean bone age was also more retarded among the patients with $\geq 7$ years of follow-up means $( \pm$ SE) of HSDS by year of follow-up, adjusted for age at treatment start, HSDS at baseline, and average GH dose. HSDS, height standard deviation score; NS, Noonan syndrome; SE, standard error; TH, target height.

than among those with $<7$ years of follow-up. Overall, $14.29 \%$ of patients with $\geq 7$ years of follow-up were born small for gestational age (SGA) compared with $4.76 \%$ in the group with $<7$ years' follow-up. Median BMI was similar between the 2 groups ( $<7$ years, $15.83 \mathrm{~kg} / \mathrm{m}^{2} ; \geq 7$ years, $15.27 \mathrm{~kg} / \mathrm{m}^{2}$ ). Data on start of puberty were available for $35 / 63$ patients with $<7$ years of follow-up and for $18 / 21$ patients with $\geq 7$ years of follow-up. From these patients, $23 \%$ of patients with $<7$ years' follow-up and $17 \%$ of patients with $\geq 7$ years' follow-up had delayed puberty.

Figure 4a illustrates the adjusted HSDS over time for the cohort of patients with $<7$ years of follow-up $(n=63)$ compared to those with $\geq 7$ years of follow-up $(n=21)$. Patients with $<7$ years of follow-up experienced a progressive increase in HSDS during up to 6 years of followup. In contrast, the growth response appeared to plateau after 6 years for patients with $\geq 7$ years of follow-up.

Effect of Puberty on the Growth Response

During the study, 46 of the 69 pre-pubertal patients entered puberty; the mean (SD) age at start of puberty 
Fig. 4. Mean adjusted HSDS according to year of follow-up and pubertal status. Mean adjusted HSDS by year of follow-up for (a) patients with $<7$ years' follow-up and patients with $\geq 7$ years' follow-up, respectively, and (b) according to pre-pubertal and pubertal status. Mean adjusted HSDS was determined using (a) national reference and (b) Noonan-specific reference data (Ranke [30]). Adjusted estimated means of HSDS by follow-up year, adjusted for age at treatment start, HSDS at baseline, and average $\mathrm{GH}$ dose. $\mathrm{GH}$, growth hormone; HSDS, height standard deviation score.

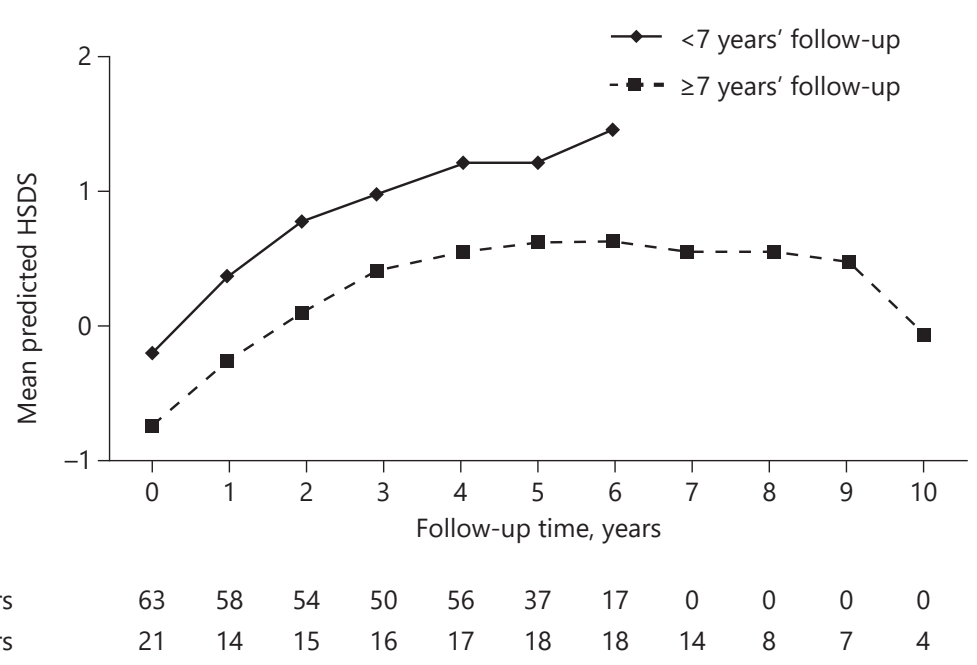

a

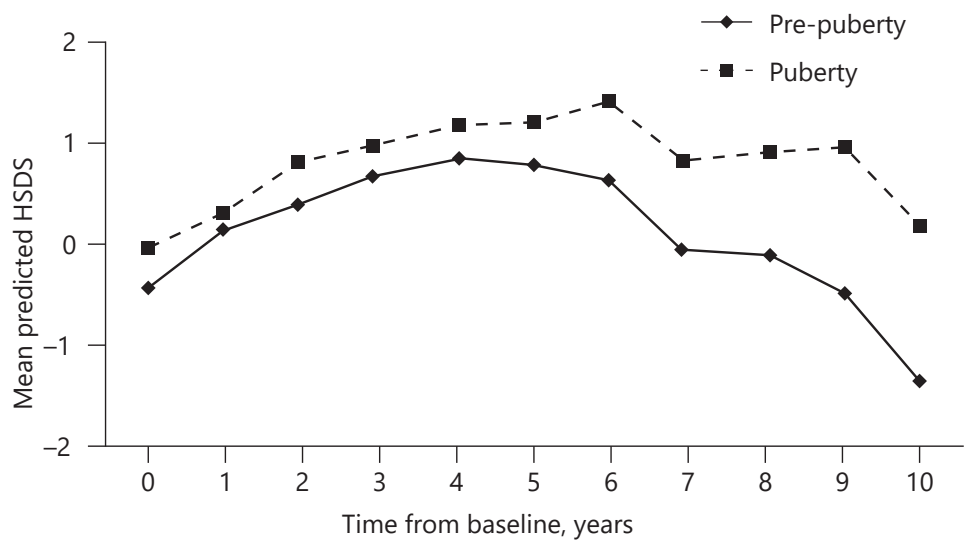

$\begin{array}{llllllllllll}\text { Pre-puberty } & 65 & 51 & 38 & 39 & 37 & 30 & 15 & 6 & 3 & 3 & 1\end{array}$ $\begin{array}{llllllllllll}\text { Puberty } & 14 & 18 & 29 & 25 & 35 & 23 & 19 & 8 & 5 & 5 & 3\end{array}$

b for these patients was 11.96 (1.38) years for female and 12.53 (1.76) years for male patients. The mean (SD) duration of $\mathrm{GH}$ treatment before start of puberty was 3.8 (2.8) years. In the cohort of 84 patients, delayed puberty (no sign of puberty in girls aged 13.0 years or in boys aged 14.0 years [32]) was reported in 3 of $14(21.4 \%)$ girls (data were missing for 3 girls) and in 8 of 39 (20.5\%) boys (data were missing for 28 boys) (Ranke reference [30]). Both pubertal and pre-pubertal patients showed an increase in predicted HSDS (Ranke reference [30]) during the first 7 years of the study (Fig. 4b). After 7 years, HSDS remained higher for pubertal than for pre-pubertal patients.

Effectiveness and Safety of Growth Hormone in Noonan Syndrome

\section{Near-Adult Height}

Baseline characteristics for patients achieving NAH are shown in online suppl. Table 3. Overall, 24 (24/266; females, $n=7$; males, $n=17$ ) patients in the total EAS achieved $\mathrm{NAH}$ by the end of the follow-up period. The mean (SD) age at start of treatment was 10.50 (3.94) years for females and 14.34 (2.22) years for males. The mean baseline HSDS was -3.09 (national references) and -0.37 (Ranke reference). Bone age was slightly retarded relative to chronological age (the mean bone age/chronological age was 0.83 ). Of the patients who achieved NAH, $42.9 \%(n=3)$ of females and $35.3 \%(n=6)$ of males were pre-pubertal at baseline (pubertal status was missing for 5 male patients and 
Table 2. Summary of safety data of patients with NS enrolled in the NordiNet ${ }^{\circledR}$ IOS and ANSWER studies

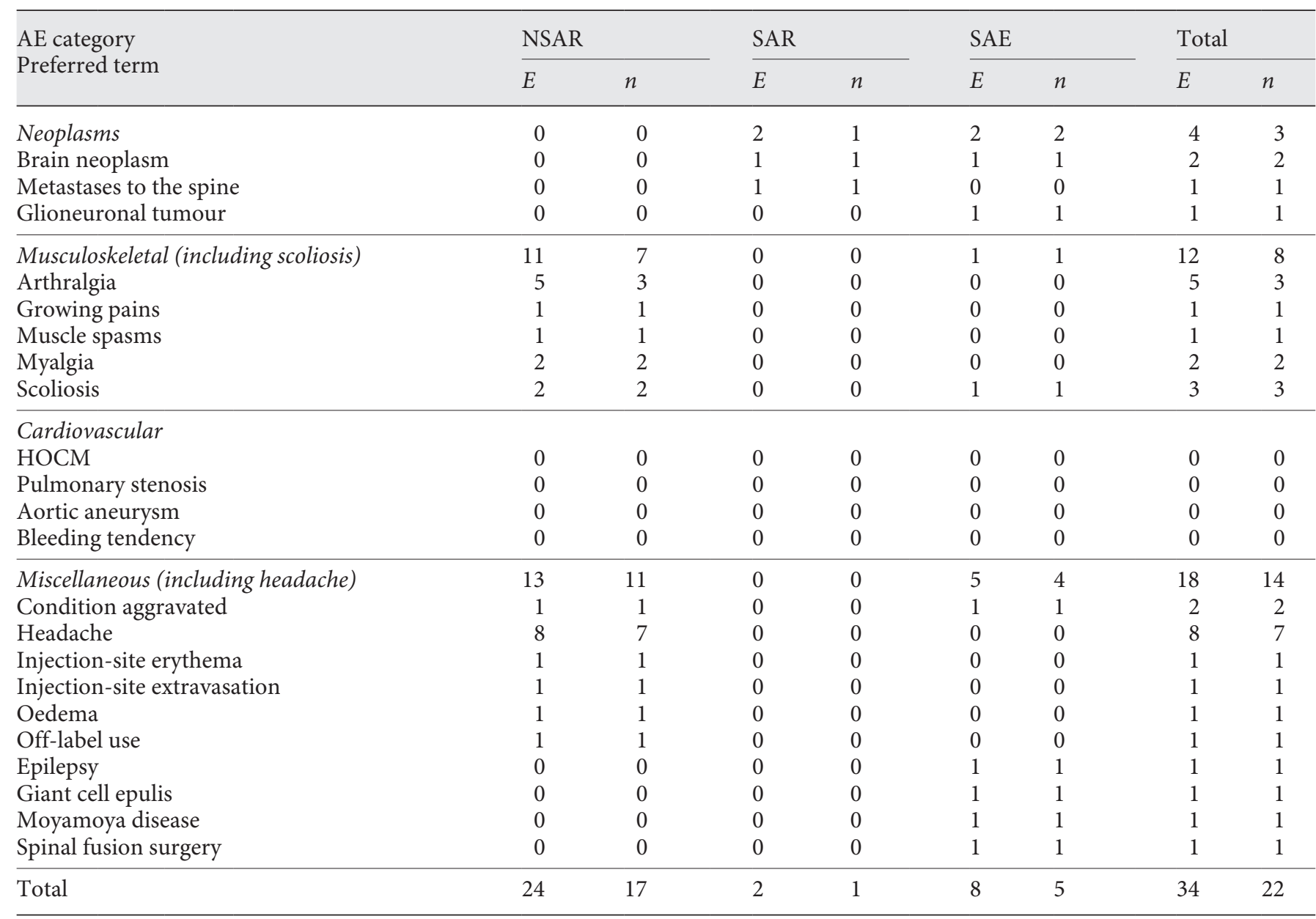

Summary of safety data collected from 412 patients with NS enrolled in 2 complementary non-interventional studies: NordiNet ${ }^{\circledR}$ IOS and ANSWER. Safety data were classified as either an NSAR and SAR, potentially related to GH therapy, or as an SAE unrelated to GH therapy. Note that no cardiovascular or vascular AEs occurred during the study period. The total number of events was additive, whereas patient numbers were not, due to the occurrence of multiple types of events in some patients. AE, adverse event; E, number of events; GH, growth hormone; HOCM, hypertrophic obstructive cardiomyopathy; HSDS, height standard deviation score; $n$, number of patients; NSAR, non-serious adverse drug reaction; SAR, serious adverse drug reaction; SAE, serious adverse event (not related to GH).

1 female patient). The mean ([SD]; range) duration of treatment to NAH was 4.8 ([2.8]; 1.8-14.7) years, and the mean (SD) baseline GH dose was $43(13) \mu \mathrm{g} / \mathrm{kg} /$ day.

The mean (SD) NAH SDS (national references) was $-1.52(0.60)(154.90[3.21] \mathrm{cm})$ in females and -1.79 (1.10) $(165.61[7.19] \mathrm{cm})$ in males. This represented a mean (SD) increase in HSDS from baseline of $1.23(0.63)$ $(30.46[21.93] \mathrm{cm})$ for females and $1.45(0.59)(25.20$ [10.56] $\mathrm{cm}$ ) for males. NAH SDS (national references) was within the normal population range $(\geq-2)$ for 17 $(70.8 \%)$ of the 24 patients. The mean ([SD]; range) age at $\mathrm{NAH}$ was 16.12 ([1.29]; 13.91-17.44) years for females and 18.58 ([1.17]; 16.61-21.00) years for males.

\section{Bone Age}

The mean (SD) bone age (years) was $7.0(3.3)(n=33)$ at baseline and $10.7(3.1)(n=19)$ after 5 years. The mean (SD) bone age/chronological age was $0.80(0.15)(n=33)$ at baseline and $0.93(0.10)(n=19)$ after 4 years' followup. After year 5 , patient numbers were too small $(n<10)$ to allow meaningful evaluation of data.

\section{Reasons for Patients Stopping Growth Hormone Treatment}

For the 84 patients in the EAS, a reason for discontinuation was available for 46 (54.8\%) and included the following: adult height reached/growth plate fusion $(n=6$; 
7.1\%), low height velocity $(n=3 ; 3.6 \%)$, and normal height reached $(n=2 ; 2.4 \%)$. Other reasons included the following: the study (NordiNet ${ }^{\circledR}$ IOS or ANSWER) was stopped $(n=26 ; 31.0 \%)$, the patient switched to another GH product $(n=4 ; 4.8 \%)$, patient choice $(n=3 ; 3.6 \%)$, funding issue/no funds for GH treatment ( $n=1 ; 1.2 \%)$, and poor adherence to $\mathrm{GH}$ treatment $(n=1 ; 1.2 \%)$.

\section{Safety}

The safety analysis included 412 patients with NS who had received at least 1 dose of GH. Overall, 34 safety events were reported in a total of $22(5.3 \%)$ patients (Table 2). The majority (24 events in 17 patients) were NSARs, of which most (20/24) had stabilized or resolved by the end of the follow-up period. The NSARs included 5 events of arthralgia in 3 patients, 8 events of headache in 7 patients, and 1 event each of growing pains, injection-site erythe$\mathrm{ma}$, and injection-site extravasation, each reported in 1 patient. Two SARs (brain neoplasm [metastatic fourth ventricular pilocytic astrocytoma] and metastases to the spine) were reported in 1 patient, and 8 SAEs were reported in 5 patients (Table 2). All SAEs were reported resolved/ resolving at the end of the follow-up period.

Brain neoplasm and metastases to the spine were reported as an SAR in a male patient aged 15.9 years who started GH therapy at 13.4 years of age. Both events were reported as not resolved at the end of the follow-up period. This patient (who carried a PTPN11 mutation) had a history of headaches, which may have suggested an underlying condition. A temporal association between reported brain neoplasm and GH treatment cannot be excluded, but further medical assessment was not reported in the database.

Epilepsy and a glioneuronal tumour were reported as an SAE in a female patient aged 9.9 years, approximately 2.5 years after starting $\mathrm{GH}$ therapy. Two months later, the condition aggravated and was reported as an SAE in the same patient. Data suggest that GH treatment was discontinued for this patient although duration of discontinuation was uncertain. The genetic status of this patient is unknown. The outcome of all 3 SAEs was reported as resolved. Brain neoplasm (male; aged 9.4 years who started GH at 8.2 years) and giant cell epulis (peripheral giant cell granuloma) (male; aged 9.7 years who started GH at 7.8 years) were also reported as SAEs.

No cases of hypertrophic cardiomyopathy, pulmonary stenosis, or aortic aneurysm were reported as an adverse drug reaction (ADR) or SAE during the study. After start of GH treatment, 5 patients were diagnosed with at least 1 (potentially pre-existing) cardiovascular comorbidity:

Effectiveness and Safety of Growth

Hormone in Noonan Syndrome unspecified cardiovascular disease $(n=3)$, ruptured abdominal aortic aneurysm $(n=1)$, and pulmonary valve stenosis $(n=1)$. The ruptured abdominal aortic aneurysm was diagnosed in a patient (PTPN11 mutation) 26 months after start of therapy. This patient was also diagnosed with Crohn's disease (22 months after start of $\mathrm{GH}$ treatment) and with a glioneuronal tumour (reported as an SAE) 1 week after the aneurysm diagnosis (online suppl. Table 2). The cerebrovascular Moyamoya disease was reported as an SAE in a female aged 10.4 years who started $\mathrm{GH}$ at 6.3 years.

Musculoskeletal events reported as an ADR or SAE during the study included 3 events of scoliosis in 3 patients (NSAR, $n=2$; SAE, $n=1$ ) and 5 events of arthralgia (all reported as an NSAR) reported in 3 patients. Scoliosis was reported as an SAE in a male aged 15.3 years who started GH at the age of 5.2 years. This patient had spinal fusion surgery at 16.5 years of age. Scoliosis was not reported at baseline in this patient.

\section{Discussion/Conclusions}

The patients treated with GH in the present study were generally representative of a population of patients with NS who are short in stature and who, if left untreated, are most likely to stay short in adult life [3]. The high proportion of male patients (80\%) is likely due to referral bias, a well-known phenomenon in GHD [33]. Diagnosis of NS for the patients in our cohort was based on the treating physician's decision according to usual clinical practice. This decision may have been based solely on clinical features in some cases. Therefore, the possibility that some patients in our study may have been misdiagnosed with NS cannot be excluded. Data on genetic mutations were available for $14.8 \%(61 / 412)$ patients. It is therefore possible that a few of the patients in our study may have been misdiagnosed with NS.

Patients responded well to GH treatment as assessed by change in HSDS from baseline (approximately 1.0 SDS after 3 years). However, the choice of reference population for growth in patients with NS is important to consider when interpreting the magnitude of GH response. This is illustrated by the difference between mean adjusted $\triangle$ HSDS at 5 years of 1.17 (national reference) and 1.46 (Ranke), although a similar effectiveness of treatment was observed irrespective of reference used. Indeed, after only 1 year on GH therapy, the NS patients were already growing better than their untreated peers with NS (according to the Ranke reference [30]) and retained this advantage 
even after 10 years of follow-up. Furthermore, even compared with national growth references, after 3 years of treatment, approximately $75 \%$ of NS patients achieved a HSDS of $>-2$ and $>70 \%$ achieved the same during subsequent 4-6-year follow-up. For reference, according to European cohorts, children with untreated NS reach median adult heights of $162.5 \mathrm{~cm}$ for men and $153.0 \mathrm{~cm}$ for women, around -2 SDS from the reference population $[27,34]$.

A pronounced difference in growth response was shown between the sub-group of patients with $<7$ years of follow-up and those with $\geq 7$ years of follow-up. Patients with $\geq 7$ years of follow-up were younger and shorter at treatment start than those with $<7$ years of follow-up. These differences in baseline characteristics may have reflected differences in genetic mutations between the subgroups [35]; however, we were not able to investigate this in our study due to the limited availability on genetic mutations collected in our study cohort. It may also be speculated that patients with more severe growth retardation are likely to present earlier with short stature and therefore start GH treatment earlier. It was also noticeable that a higher proportion of patients with $\geq 7$ years of follow-up versus $<7$ years' follow-up were born SGA, which may have affected the growth response [3]. There was no difference between these 2 groups with respect to the proportions of patients with delayed puberty.

There was catch-up in HSDS during the first 3 years of the study, after which the growth rate plateaued. If not treated, these patients may have lost height relative to their non-NS peers [30]. The mean increase in HSDS of 1.01 (national references) at 3 years compares favourably with a study in which a mean $\triangle$ HSDS of +0.8 (from -2.7 to -1.9 SDS) was reported after 3 years of GH treatment [13]. Skeletal maturity is delayed in individuals with NS [6], but reassuringly, we did not observe inappropriate advancement in bone age during GH therapy in our study cohort. Mean height in untreated patients with NS follows the third percentile (approximately -2 SDS) during the first years of life. There is usually a further decline in height at the start of puberty [30], the onset of which is delayed for a large proportion of patients with NS [23]. In our study, the mean (SD) age for start of puberty was 11.96 (1.38) years for females and 12.53 (1.76) years for males, consistent with reported NS results indicating that the mean age at pubertal onset is 11-14 years in females and $12-16$ years in males $[17,18,34]$. In healthy children, most girls enter puberty between 10 and 11 years while most boys enter puberty between the ages of 11 and 12 years [36]. In our study, delayed puberty was observed in $21.4 \%$ of girls and $20.5 \%$ of boys. Although delayed puberty is reported as common in children with NS [34], there are few data on the frequency of this condition in patients. In a retrospective analysis of 84 patients with NS, delayed puberty was reported in $23 \%$ of girls and in $36 \%$ of boys [22]. These data are not dissimilar to those reported in our study, especially given that data on pubertal onset were missing for $41.8 \%(28 / 67)$ boys. Puberty in NS patients may progress rapidly ( $<2$ years) and is often characterized by a diminished pubertal growth spurt [20]. The NS-specific references reflect the delayed puberty seen in patients with NS commonly by up to 2 years and with growth, especially for males, that continues into their twenties [30]. We observed a greater adjusted HSDS in pubertal compared with pre-pubertal patients. Longer follow-up of these pre-pubertal patients is warranted to determine the pattern of their growth and their adult height.

Approximately $25 \%$ of our study cohort achieved NAH during the follow-up period. The median gain in HSDS (national references) from treatment start was 1.4 ([mean] females, $1.2[30.46 \mathrm{~cm}]$; males, $1.4[25.20 \mathrm{~cm}]$ ), and the mean NAH was -1.5 ([mean] females, -1.5 $[154.90 \mathrm{~cm}]$; males, $-1.8[165.60 \mathrm{~cm}])$. For $71 \%(17 / 24)$ of the patients who achieved NAH, HSDS (NS-specific reference) was within the normal population range $(\geq-2)$. In our cohort, we carefully screened growth data of all patients to ensure that growth had slowed sufficiently to be confident that NAH had been achieved: the mean age at NAH was 16.1 years for females and 18.6 years for males, in accordance with Kabi International Growth Study (KIGS) NS results (females, 16.5 years; males, 18.2 years) [23]. In most reported studies, the mean NAH SDS reached was 2 SD below the population average and the overall gain was around 1.3 SD. Osio et al. [17] reported the highest gains in 25 patients who started GH therapy between 6.9 and 8.7 years of age and who were treated for a mean duration of 7.5 years. For these patients, mean (SD) HSDS increased from $-2.9(0.4)$ at baseline to $-1.2(1.0)$ at final height. As the tempo of growth seems to be delayed in NS, the issue of adult height in these patients is challenging because it is usually achieved later than in patients without NS. Therefore, the definition of NAH in NS patients may differ from that in other populations $[19,20,23]$.

The NS findings in our study are in line with NAH SDS data reported from the National Cooperative Growth Study (NCGS; $n=65)$ [20], while in KIGS $(n=402)$ [19], $\mathrm{NAH}$ height outcomes were slightly lower than those reported here. In the NCGS, the mean (SD) NAH SDS 
was -2.1 (1.0), a mean gain of 1.4 (0.7) SDS from baseline [20] using US growth references [37], while in KIGS, the median gain in HSDS was 0.61 (national reference) and 0.91 (NS-specific reference). The mean incremental height gain in NAH above projected height for patients in the NCGS was $10.9 \mathrm{~cm}$ for males and $9.2 \mathrm{~cm}$ for females using the NS-specific references [30] and $8.9 \mathrm{~cm}$ for males and $10.0 \mathrm{~cm}$ for females using the CDC references [37]. In our study, even after 10 years of follow-up, the HSDS was approximately $1 \mathrm{SD}$ above that of untreated patients with NS. Differences in growth outcomes may be a consequence of differences in the study populations, as well as in treatment duration and GH dosing. In the NCGS, patients received a mean GH dose of $47 \mu \mathrm{g} / \mathrm{kg} /$ day for 5.6 years [20], and in KIGS, patients received $34 \mu \mathrm{g} / \mathrm{kg} /$ day for 3 years [19], compared to a mean dose of $41.64 \mu \mathrm{g} / \mathrm{kg} / \mathrm{day}$ for 5.7 years in the present study. Patients in our study were younger at treatment start (8.4 years) than in NCGS (11.6 years) [20] or KIGS (9.7 years) [19]. Age at treatment initiation is 1 of the factors known to affect height gain during $\mathrm{GH}$ treatment in patients with NS [23] and in patients with GHD [38]. Other factors that may influence growth include age at onset of puberty $[30,39]$ and molecular genetics. Ranke and colleagues [23] reported that $36 \%$ of the variability in firstyear height velocity could be attributed to age at the start of GH (negative), height at the start of GH, GH dose, number of GH injections/week, and birth weight (all positive) $(n=613)$. In the same study, $74 \%$ of the variability in NAH was attributed to height at the start of $\mathrm{GH}$, first-year growth on $\mathrm{GH}$, birth weight, and gender [23]. Both age (the younger the better) and height (the taller the better) at start of GH treatment were also shown to be important factors in our analyses. It has been suggested that patients with NS with PTPN11 mutations may respond better to GH therapy than patients with other mutations [22]. Overall, since genetic mutation data were available for 61 patients in our study, of whom 4 were included in the EAS, we were unable to evaluate differences in response to $\mathrm{GH}$ treatment by genetic mutation.

The safety data collected in our study were overall similar to that reported in patients with NS in the NCGS $(n=370)$ [20]. The ADRs reported most were non-serious and were events that have previously been reported in patients with NS receiving GH $[20,40]$ or in GH-treated children $[41,42]$ such as headache, arthralgia, and injection-site related events. Patients with NS have an inherent risk for cardiac [43, 44] and haematological [45] comorbidities, as well as an increased risk for malignancy $[26,46-48]$, especially central nervous system (CNS) tumours $[26,49,50]$.

Effectiveness and Safety of Growth

Hormone in Noonan Syndrome
In our study, only 1 vascular $\mathrm{AE}$ was reported during GH treatment: a case of Moyamoya disease, reported as an SAE in the nervous system, unrelated to GH therapy. Moyamoya disease has previously been reported in patients with NS [51]. After GH start, 5 patients were diagnosed with cardiovascular comorbidities that might have been pre-existing. Cardiac comorbidities were likely to have been under-reported at $8.3 \%$, considering the reported frequency of $80 \%$ in NS in other studies [43,44]. No cases of hypertrophic cardiomyopathy were reported in our study. The estimated prevalence of hypertrophic cardiomyopathy in patients with NS is $20 \%$, with $50 \%$ of these patients also having congenital heart defects [52]. Pulmonary valve stenosis and atrial septal defect have been reported in up to 57 and $32 \%$ of NS patients, respectively [43]. A ruptured abdominal aortic aneurysm was reported as a cardiovascular comorbidity in 1 patient in our study. Aortic aneurysm has previously been described in both adult and child patients with NS $[53,54]$. No evidence of an adverse effect of GH on cardiac structure or function has been described, based on current experience in the limited numbers of patients [55-57].

Scoliosis was reported as an AE during GH treatment in 3 patients in our study. Of these, 2 events were considered non-serious and possibly related to GH treatment. The third case was considered serious but unrelated to $\mathrm{GH}$ treatment and later required spinal surgery. None of these patients had a diagnosis of scoliosis before $\mathrm{GH}$ treatment start. One patient reported scoliosis prior to GH start, but no worsening of this condition was reported during the study. The estimated prevalence of scoliosis in patients with NS is 30\% [7]. Romano et al. [20] reported 6 cases of scoliosis in 370 patients during a mean $\mathrm{GH}$ treatment period of 5.6 years, and Kirk et al. [16] reported 1 case of worsening kyphoscoliosis among 66 patients who were treated with GH for up to 6 years.

The underlying pathophysiology of NS includes dysregulation of the Ras/mitogen-activated protein kinase signalling pathway, which may increase the intrinsic risk for cancer [48]. The risk of developing cancer was estimated as 3.5-fold higher among 297 individuals with a PTPN11 mutation than in the general population [9] and as 8.0-fold higher among 632 individuals with molecularly defined NS compared with individuals without NS [8]. In particular, NS is associated with a higher risk of benign and malignant proliferative disorders [9], including solid tumours [8,26] and soft tissue tumours [47], and glioneuronal tumour and astrocytoma [9]. The solid tumours include neuroblastoma and CNS tumours such as low-grade dysembryoplastic neuroepithelial tumours 
(DNETs) and gliomas [58]. It is likely that the association of DNETs with NS is valid considering the rare occurrence of DNETs in the general paediatric population (about 1.5\% of paediatric brain tumours) [59] compared with the occurrence of DNETs in NS (approximately $40 \%$ of all CNS neoplasms reported) [26]. In our study, under the MedDRA term "neoplasms, benign, malignant, and unspecified," 4 events reported in 3 patients $(3 / 412 ; 0.7 \%)$ comprised brain neoplasm (reported as an SAE, unlikely related to $\mathrm{GH}$ treatment) in 1 patient, glioneuronal tumour (reported as an SAE, unlikely related to GH treatment) in 1 patient, and 1 event each of brain neoplasm and metastases to the spine both reported as an SAR (possibly related to $\mathrm{GH}$ treatment) in 1 patient. This appears to be lower than the incidence reported by Kratz et al. [8] among patients with NS in Germany (8 events in 632 patients). However, larger numbers of events and patients would be needed to confirm differences in incidence and the relationship with GH therapy with certainty. Previous reports of CNS tumours in patients with NS receiving GH therapy include 2 patients with NS who developed different primary brain tumours while on GH therapy [49]. Furthermore, accumulated evidence suggests that there may be differences in susceptibility to cancer types between somatic and germline mutations [60]. The available data on GH and cancer risk are reassuring, but underlying susceptibility to tumour growth should be considered when GH therapy is started $[49,50]$. With respect to the possible association of NS and primary brain tumours, recent recommendations suggest obtaining a magnetic resonance image of the brain prior to initiation of GH treatment in patients with NS, particularly in those with PTPN11 mutation, as they appear to have an increased risk for cranial neoplasms [49].

Headache was the most frequently reported NSAR in the present study. Although a common event, a report in a small number of patients $(n=22)$ documented a potential increased incidence of migraine, which might be reported as headache, among patients with NS [61]. Further studies are needed to confirm this observation.

Reassuringly, no patients reported stopping study participation due to AEs and, for most, treatment was continued until the study was stopped (although they may have continued treatment outside the study) or a satisfactory height outcome was achieved.

Data collected in our study were limited to the duration of GH treatment and therefore cannot be applied to assess the safety of prior GH treatment in NS patients after GH is stopped. Furthermore, as seen in many observational studies, there may have been an under-reporting of safety data. Other limitations of large, multi-centre, observational studies may also be applicable, including the absence of data on treatment adherence, potential changes in diagnostic practices, and definitions of eligibility for $\mathrm{GH}$ treatment, as well as changes in prescribing practices due to financial constraints or external influences that may have differed by country between 2002 and 2016 . Comorbidities and AEs may have been under-reported or reported differently according to local practice, as acknowledged in similar registries such as GeNeSIS [62] and KIGS [63]. The lack of genetic data for all patients included in the analyses prevented investigation of treatment response and safety for sub-groups of patients diagnosed with NS.

Nevertheless, the 2 similar studies in different geographic regions provide a wealth of real-world data. The data describe the characteristics of patients whom clinicians could expect to meet in everyday clinical practice and highlight areas where improvements could be considered, such as earlier initiation of treatment in patients. The results also provide reassurance regarding the safety of GH in a large population of patients with NS, although underlying susceptibility to tumour growth should be considered when GH therapy is started [64], and appropriate surveillance during GH treatment may be considered. Furthermore, in recognition of the increased susceptibility of some patients with specific genetic mutations to a higher risk for certain cancers, genetic testing may provide information on the background risk at the start of treatment. Finally, while the population of patients with NS in our cohort is more heterogeneous than it would be in a single-region study, the larger numbers of patients in our study facilitate analysis of the effectiveness and safety of GH therapy in patients with NS.

In summary, these data confirm that $\mathrm{GH}$ treatment is associated with an increase in HSDS during childhood and suggest improvement in adult height. The data suggest that earlier start of GH therapy may be an important contributor to height optimization by normalizing height at pubertal onset, especially with respect to the known delay in puberty in patients with NS. The safety data are reassuring regarding the long-term safety of GH therapy in this population. This study has produced no evidence to support a higher prevalence of neoplasm and cardiac or other comorbidities in patients with NS who have been treated with GH. There is a complex safety profile in NS in relation to the background risk of this disorder that should be better defined by genetic analysis and longterm follow-up of the patients. 


\section{Acknowledgements}

The authors would like to thank the patients, their families, the nurses and study coordinators, and all investigators involved in this study. Statistical support was provided by Jean-Marc Ferran (Qualiance ApS) and Moshe Fridman (AMF Consulting), both under contract to Novo Nordisk A/S. Medical writing and editorial support were provided by Penny Butcher, $\mathrm{PhD}$, and Helen Marshall of Watermeadow Medical, part of the Ashfield Group, supported by Novo Nordisk Health Care AG. The sponsor was involved in the study design and collection, analysis, and interpretation of data, as well as data checking of information provided in the manuscript. However, ultimate responsibility for opinions, conclusions, and data interpretation lies with the authors. This work was dedicated to the memory of Dr. Jacqueline Noonan (1928-2020).

\section{Statement of Ethics}

Approval was obtained from relevant ethics committees, written informed consent was obtained, and all data were anonymized. This study was conducted in accordance with the Declaration of Helsinki and was approved by the local Institutional Ethics Committee/Institutional Review Board and the local regulatory authorities at each study centre and data privacy agencies as required. NordiNet ${ }^{\circledR}$ IOS and ANSWER were conducted in accordance with the Good Pharmacoepidemiology Practice guidelines [65].

\section{Conflict of Interest Statement}

Tilman R. Rohrer has acted as a consultant for Novo Nordisk and received speaker honoraria from Novo Nordisk. M. Jennifer Abuzzahab has received research grant/research support from Ascendis, Astra Zeneca, Levo, Millendo, Novo Nordisk, Rhythm, and Soleno. She has attended advisory boards for Ascendis and Rhythm and speaker's bureau for Novo Nordisk, Rhythm, and Sandoz. Philippe Backeljauw has received research grant support from Novo Nordisk, Opko, and Ipsen and is a consultant for Novo Nordisk, Ipsen, Sandoz, and Endo Pharmaceuticals. Anna Camilla Birkegård, Vlady Ostrow, and Alberto Pietropoli are employees of Novo Nordisk. Jo Blair has acted as a consultant for Novo Nordisk, has received speaker honoraria from Novo Nordisk and Sandoz, and has received financial support in the form of registration fees from Novo Nordisk to attend academic meetings. Jovanna Dahlgren has received honoraria from Merck, Novartis, and Pfizer, as well as unrestricted grants from Pfizer for 2 clinical trials. Petur B. Juliusson has received a lecture fee from Novo Nordisk for a presentation at a Novo Nordisk meeting. Michel Polak is a member of the Increlex European registry and Novo Nordisk growth international advisory board and has institutional disclosures from Pfizer France. He has received grants from Ipsen, Novo Nordisk, Pfizer, Lilly, Sanofi, Sandoz, and Merck and government grants (PHRC, PHRIP, and ANR). Alicia Romano has been a consultant for Ascendis Pharma and is a consultant and speaker for Novo Nordisk. Judith Ross is a consultant for Novo Nordisk and Opko and receives research funding from Novo Nordisk. Lars Sävendahl has received consultancy fees from Ascendis, Hexal,
Novo Nordisk, Merck, Pfizer, and Sandoz. Bradley S. Miller has been a consultant for Ascendis, BioMarin, Bluebird Bio, GeneScience, Novo Nordisk, Pfizer, Sandoz, Sanofi Genzyme, Soleno, Takeda, Tolmar, and Versartis and has received research support from AbbVie, Alexion, Ascendis, Novo Nordisk, Opko, Orphan Reach, Sandoz, Sangamo, Sanofi Genzyme, Takeda, and Versartis in the last 3 years.

\section{Funding Sources}

Design and conduct of the study: NordiNet ${ }^{\circledR}$ IOS was designed by the sponsor Novo Nordisk A/S. The ANSWER study was designed by Novo Nordisk Inc. Collection, management, analysis, and interpretation of the data: For NordiNet ${ }^{\circledR}$, the NordiNet ${ }^{\circledR}$ web application facilitated data entry at each individual study site. The physician entered data using an electronic case report form and exported it to the NordiNet ${ }^{\circledR}$ International Outcomes Database (IODB), which was owned by Novo Nordisk and hosted by NNIT/ Rackspace. Data were protected by an individual user ID and password. During the early years of the study, standalone laptops were used and the anonymized data were exported and transferred in an encrypted format to the NordiNet ${ }^{\circledR}$ IODB. Data from the national German Novo Nordisk non-interventional studies on patients treated with Norditropin, GrowthWin (initiated in 2001) and NordiWin (initiated in 2003), were also migrated into the NordiNet ${ }^{\circledR}$ IODB.

\section{Author Contributions}

Concept and design and acquisition, analysis, or interpretation of data: Tilman R. Rohrer, M. Jennifer Abuzzahab, Philippe Backeljauw, Anna Camilla Birkegård, Jo Blair, Jovanna Dahlgren, Petur B. Juliusson, Vlady Ostrow, Alberto Pietropoli, Michel Polak, Alicia Romano, Judith Ross, Lars Sävendahl, and Bradley S. Miller. Drafting of the manuscript: see Acknowledgements. Critical revision of the manuscript for important intellectual content: Tilman R. Rohrer, M. Jennifer Abuzzahab, Philippe Backeljauw, Anna Camilla Birkegård, Jo Blair, Jovanna Dahlgren, Petur B. Juliusson, Vlady Ostrow, Alberto Pietropoli, Michel Polak, Alicia Romano, Judith Ross, Lars Sävendahl, and Bradley S. Miller. Statistical analysis: Anna Camilla Birkegård (see Acknowledgements). Administrative, technical, or material support: Vlady Ostrow and Alberto Pietropoli. Supervision: Vlady Ostrow and Alberto Pietropoli.

\section{References}

Horm Res Paediatr 2020;93:380-395

DOI: $10.1159 / 000512429$

Noonan JA, Ehmke DA. Associated noncardiac malformations in children with congenital heart disease. J Pediatr. 1963;63:468-70.

2 Binder G. Noonan syndrome, the Ras-MAPK signalling pathway and short stature. Horm Res. 2009 Apr;71(Suppl 2):64-70.

3 Cessans C, Ehlinger V, Arnaud C, Yart A, Capri Y, Barat P, et al. Growth patterns of patients with Noonan syndrome: correlation with age and genotype. Eur J Endocrinol. 2016 May;174(5):641-50.
Effectiveness and Safety of Growth

Hormone in Noonan Syndrome 
4 De Rocca Serra-Nedelec A, Edouard T, Treguer K, Tajan M, Araki T, Dance M, et al. Noonan syndrome-causing SHP2 mutants inhibit insulin-like growth factor 1 release via growth hormone-induced ERK hyperactivation, which contributes to short stature. Proc Natl Acad Sci U S A. 2012 Mar 13;109(11): 4257-62.

5 Shaw AC, Kalidas K, Crosby AH, Jeffery S, Patton MA. The natural history of Noonan syndrome: a long-term follow-up study. Arch Dis Child. 2007 Feb;92(2):128-32.

6 Roberts AE, Allanson JE, Tartaglia M, Gelb BD. Noonan syndrome. Lancet. 2013 Jan 26; 381(9863):333-42.

7 Lee C-K, Chang B-S, Hong Y-M, Yang SW, Lee C-S, Seo J-B. Spinal deformities in noonan syndrome: a clinical review of sixty cases. JBJS. 2001;83(10): 1495-502.

8 Kratz CP, Franke L, Peters H, Kohlschmidt N, Kazmierczak B, Finckh U, et al. Cancer spectrum and frequency among children with Noonan, Costello, and cardio-facio-cutaneous syndromes. Br J Cancer. 2015 Apr 14; 112(8):1392-7.

9 Jongmans MC, van der Burgt I, Hoogerbrugge PM, Noordam K, Yntema HG, Nillesen WM, et al. Cancer risk in patients with Noonan syndrome carrying a PTPN11 mutation. Eur J Hum Genet. 2011 Aug;19(8):870-4.

10 Ahmed ML, Foot AB, Edge JA, Lamkin VA, Savage MO, Dunger DB. Noonan's syndrome: abnormalities of the growth hormone/IGF-I axis and the response to treatment with human biosynthetic growth hormone. Acta Paediatr Scand. 1991 Apr;80(4):446-50.

11 Cotterill AM, McKenna WJ, Brady AF, Sharland M, Elsawi M, Yamada M, et al. The shortterm effects of growth hormone therapy on height velocity and cardiac ventricular wall thickness in children with Noonan's syndrome. J Clin Endocrinol Metab. 1996 Jun; 81(6):2291-7.

12 De Schepper J, Otten BJ, François I, Bourguignon JP, Craen M, Van der Burgt I, et al. Growth hormone therapy in pre-pubertal children with Noonan syndrome: first year growth response and comparison with Turner syndrome. Acta Paediatr. 1997 Sep;86(9): 943-6.

13 MacFarlane CE, Brown DC, Johnston LB, Patton MA, Dunger DB, Savage MO, et al. Growth hormone therapy and growth in children with Noonan's syndrome: results of 3 years' follow-up. J Clin Endocrinol Metab. 2001 May;86(5):1953-6.

14 Lee PA, Ross J, Germak JA, Gut R. Effect of 4 years of growth hormone therapy in children with Noonan syndrome in the American Norditropin Studies: Web-Enabled Research (ANSWER) Program(R) registry. Int J Pediatr Endocrinol. 2012 Jun;2012(1):15.

15 Municchi G, Pasquino AM, Pucarelli I, Cianfarani S, Passeri F. Growth hormone treatment in Noonan syndrome: report of four cases who reached final height. Horm Res. 1995;44(4):164-7.
16 Kirk JM, Betts PR, Butler GE, Donaldson MD, Dunger DB, Johnston DI, et al. Short stature in Noonan syndrome: response to growth hormone therapy. Arch Dis Child. 2001; 84(5):440-3.

17 Osio D, Dahlgren J, Wikland KA, Westphal O. Improved final height with long-term growth hormone treatment in Noonan syndrome. Acta Paediatr. 2005 Sep;94(9):1232-7.

18 Noordam C, Peer PG, Francois I, De Schepper J, van den Burgt I, Otten BJ. Long-term GH treatment improves adult height in children with Noonan syndrome with and without mutations in protein tyrosine phosphatase, non-receptor-type 11. Eur J Endocrinol. 2008 Sep;159(3):203-8.

19 Raaijmakers R, Noordam C, Karagiannis G, Gregory JW, Hertel NT, Sipilä I, et al. Response to growth hormone treatment and final height in Noonan syndrome in a large cohort of patients in the KIGS database. J Pediatr Endocrinol Metab. 2008 Mar;21(3): $267-73$.

20 Romano AA, Dana K, Bakker B, Davis DA, Hunold JJ, Jacobs J, et al. Growth response, near-adult height, and patterns of growth and puberty in patients with noonan syndrome treated with growth hormone. J Clin Endocrinol Metab. 2009 Jul;94(7):2338-44.

21 Tamburrino F, Gibertoni D, Rossi C, Scarano E, Perri A, Montanari F, et al. Response to long-term growth hormone therapy in patients affected by RASopathies and growth hormone deficiency: patterns of growth, puberty and final height data. Am J Med Genet A. 2015 Nov;167A(11):2786-94.

22 Malaquias AC, Noronha RM, Souza TTO, Homma TK, Funari MFA, Yamamoto GL, et al. Impact of growth hormone therapy on adult height in patients with PTPN11 mutations related to Noonan syndrome. Horm Res Paediatr. 2019;91(4):252-61.

23 Ranke MB, Lindberg A, Carlsson M, Camacho-Hübner C, Rooman R. Treatment with growth hormone in Noonan syndrome observed during 25 years of KIGS: near adult height and outcome prediction. Horm Res Paediatr. 2019;91(1):46-55.

24 Horikawa R, Ogata T, Matsubara Y, Yokoya S, Ogawa Y, Nishijima K, et al. A trial investigating the long-term efficacy and safety of two doses of Norditropin ${ }^{\circledR}$ (somatropin; recombinant human growth hormone) in Japanese children with short stature due to Noonan syndrome over four years of treatment. Horm Res Paediatr. 2019;91(Suppl 1):345.

25 Noordam C, Van der Burgt I, Sengers RC, Delemarre-van de Waal HA, Otten BJ. Growth hormone treatment in children with Noonan's syndrome: four year results of a partly controlled trial. Acta Paediatr. 2001 Aug;90(8):889-94.

26 McWilliams GD, SantaCruz K, Hart B, Clericuzio $C$. Occurrence of DNET and other brain tumors in Noonan syndrome warrants caution with growth hormone therapy. Am J Med Genet A. 2016 Jan;170A(1):195-201.
27 Lee PA, Ross JL, Pedersen BT, Kotnik P, Germak JA, Christesen HT. Noonan syndrome and Turner syndrome patients respond similarly to 4 years' growth-hormone therapy: longitudinal analysis of growth-hormone-naive patients enrolled in the NordiNet(R) International Outcome Study and the ANSWER Program. Int J Pediatr Endocrinol. 2015;2015(1):17.

28 Hoybye C, Savendahl L, Christesen HT, Lee P, Pedersen BT, Schlumpf $M$, et al. The NordiNet(R) International Outcome Study and NovoNet(R) ANSWER Program(R): rationale, design, and methodology of two international pharmacoepidemiological registry-based studies monitoring long-term clinical and safety outcomes of growth hormone therapy (Norditropin(R)). Clin Epidemiol. 2013;5:119-27.

29 Blankenstein O, Pedersen BT, Schlumpf M, Andreasen AH, Juliusson PB. Management and interpretation of heterogeneous observational data: using insulin-like growth factor-I data from the NordiNet(R) International Outcome Study. Growth Horm IGF Res. 2015 Feb;25(1):41-6.

30 Ranke MB, Heidemann P, Knupfer C, Enders $\mathrm{H}$, Schmaltz AA, Bierich JR. Noonan syndrome: growth and clinical manifestations in 144 cases. Eur J Pediatr. 1988 Dec;148(3):220-7.

31 Tanner JM, Goldstein H, Whitehouse RH. Standards for children's height at ages 2-9 years allowing for heights of parents. Arch Dis Child. 1970 Dec;45(244):755-62.

32 Traggiai C, Stanhope R. Disorders of pubertal development. Best Pract Res Clin Obstet Gynaecol. 2003 Feb;17(1):41-56.

33 Grimberg A, Huerta-Saenz L, Grundmeier R, Ramos MJ, Pati S, Cucchiara AJ, et al. Gender bias in U.S. pediatric growth hormone treatment. Sci Rep. 2015 Jun 9;5:11099.

34 Romano AA, Allanson JE, Dahlgren J, Gelb BD, Hall B, Pierpont ME, et al. Noonan syndrome: clinical features, diagnosis, and management guidelines. Pediatrics. 2010 Oct; 126(4):746-59.

35 Shoji Y, Ida S, Niihori T, Aoki Y, Okamoto N, Etani Y, et al. Genotype-phenotype correlation analysis in Japanese patients with Noonan syndrome. Endocrine J. 2019 Nov 28; 66(11):983-94.

36 Zacharin M, Banerjee I, Patel L. Chapter 2: puberty: normal and abnormal. In: Zacharin $M$, editor. Practical pediatric endocrinology in a limited resource setting. San Diego: Academic Press; 2013. p. 27-67.

37 Kuczmarski RJ, Ogden CL, Guo SS, Grummer-Strawn LM, Flegal KM, Mei Z, et al. 2000 CDC growth charts for the United States: methods and development. Vital Health Stat 11. 2002 May;(246):1-190

38 Polak M, Blair J, Kotnik P, Pournara E, Pedersen BT, Rohrer TR. Early growth hormone treatment start in childhood growth hormone deficiency improves near adult height: analysis from NordiNet(R) International Outcome Study. Eur J Endocrinol. 2017 Nov;177(5): 421-9. 
39 Otten BJ, Noordam C. Growth in Noonan syndrome. Horm Res. 2009 Dec;72(Suppl 2): 31-5.

40 Cappa M, Iughetti L, Loche S, Maghnie M, Vottero A. Efficacy and safety of growth hormone treatment in children with short stature: the Italian cohort of the GeNeSIS clinical study. J Endocrinol Invest. 2016 Jun;39(6): 667-77.

41 Clayton PE, Cowell CT. Safety issues in children and adolescents during growth hormone therapy: a review. Growth Horm IGF Res. 2000 Dec;10(6):306-17.

42 Savendahl L, Pournara E, Pedersen BT, Blankenstein $\mathrm{O}$. Is safety of childhood growth hormone therapy related to dose? Data from a large observational study. Eur J Endocrinol. 2016 May; 174(5):681-91.

43 Prendiville TW, Gauvreau K, Tworog-Dube E, Patkin L, Kucherlapati RS, Roberts AE, et al. Cardiovascular disease in Noonan syndrome. Arch Dis Child. 2014 Jul;99(7):62934.

44 Calcagni G, Limongelli G, D’Ambrosio A, Gesualdo F, Digilio MC, Baban A, et al. Cardiac defects, morbidity and mortality in patients affected by RASopathies. CARNET study results. Int J Cardiol. 2017 Oct 15;245: 92-8.

45 Perez Botero J, Ho TP, Rodriguez V, Khan SP, Pruthi RK, Patnaik MM. Coagulation abnormalities and haemostatic surgical outcomes in 142 patients with Noonan syndrome. Haemophilia. 2017 May;23(3):e237-40.

46 Hasle H. Malignant diseases in Noonan syndrome and related disorders. Horm Res. 2009 Dec;72(Suppl 2):8-14.

47 Moos D, Droitcourt C, Rancherevince D, Marec Berard P, Skowron F. Atypical granular cell tumor occurring in an individual with Noonan syndrome treated with growth hormone. Pediatr Dermatol. 2012 Sep-Oct; 29(5):665-6.
48 Smpokou P, Zand DJ, Rosenbaum KN, Summar ML. Malignancy in Noonan syndrome and related disorders. Clin Genet. 2015 Dec; 88(6):516-22.

49 Bangalore Krishna K, Pagan P, Escobar O, Popovic J. Occurrence of cranial neoplasms in pediatric patients with noonan syndrome receiving growth hormone: is screening with brain MRI prior to initiation of growth hormone indicated? Horm Res Paediatr. 2017; 88(6):423-6.

50 Jacquinet A, Bonnard A, Capri Y, Martin D, Sadzot B, Bianchi E, et al. Oligo-astrocytoma in LZTR1-related Noonan syndrome. Eur J Med Genet. 2020 Jan;63(1):103617.

51 Lo FS, Wang CJ, Wong MC, Lee NC. Moyamoya disease in two patients with Noonanlike syndrome with loose anagen hair. Am J Med Genet A. 2015 Jun;167(6):1285-8.

52 Gelb BD, Roberts AE, Tartaglia M. Cardiomyopathies in Noonan syndrome and the other RASopathies. Prog Pediatr Cardiol. 2015;39(1):13-9.

53 Cury M, Zeidan F, Lobato AC. Aortic disease in the young: genetic aneurysm syndromes, connective tissue disorders, and familial aortic aneurysms and dissections. Int J Vasc Med. 2013;2013:267215

54 Cornwall JW, Green RS, Nielsen JC, Gelb BD. Frequency of aortic dilation in Noonan syndrome. Am J Cardiol. 2014 Jan 15;113(2): $368-71$.

55 Noordam C. Growth hormone and the heart in Noonan syndrome. Horm Res. 2009 Dec; 72(Suppl 2):49-51.

56 Zavras N, Meazza C, Pilotta A, Gertosio C Pagani S, Tinelli C, et al. Five-year response to growth hormone in children with Noonan syndrome and growth hormone deficiency. Ital J Pediatr. 2015 Oct 6;41:71.

57 Ozono K, Ogata T, Horikawa R, Matsubara Y, Ogawa Y, Nishijima K, et al. Efficacy and safety of two doses of Norditropin ${ }^{\circledR}$ (somatropin) in short stature due to Noonan syndrome: a 2-year randomized, double-blind, multicenter trial in Japanese patients. Endocrine J. 2018 Feb 26;65(2):159-74.
58 El-Ayadi M, Ansari M, Kuhnol CD, Bendel A, Sturm D, Pietsch T, et al. Occurrence of highgrade glioma in Noonan syndrome: report of two cases. Pediatr Blood cancer. 2019 May; 66(5):e27625.

59 Taratuto AL, Pomata H, Sevlever G, Gallo G, Monges J. Dysembryoplastic neuroepithelial tumor: morphological, immunocytochemical, and deoxyribonucleic acid analyses in a pediatric series. Neurosurgery. 1995 Mar; 36(3):474-81.

60 Aoki Y, Niihori T, Narumi Y, Kure S, Matsubara Y. The RAS/MAPK syndromes: novel roles of the RAS pathway in human genetic disorders. Hum Mutat. 2008 Aug;29(8):9921006.

61 Piovesan EJ, Young Blood MR, Kowacs PA, Mulinari RA, Werneck LC, Sandrini R. Prevalence of migraine in Noonan syndrome. Cephalalgia. 2007 Apr;27(4):330-5.

62 Child CJ, Zimmermann AG, Chrousos GP, Cummings E, Deal CL, Hasegawa T, et al. Safety outcomes during pediatric $\mathrm{GH}$ therapy: final results from the prospective GeNeSIS observational program. J Clin Endocrinol Metab. 2019 Feb 1;104(2):379-89.

63 Darendeliler F, Karagiannis G, Wilton P. Headache, idiopathic intracranial hypertension and slipped capital femoral epiphysis during growth hormone treatment: a safety update from the KIGS database. Horm Res. 2007;68(Suppl 5):41-7.

64 Noonan JA, Kappelgaard AM. The efficacy and safety of growth hormone therapy in children with noonan syndrome: a review of the evidence. Horm Res Paediatr. 2015;83(3): 157-66.

65 Public Policy Committee' International Society of Pharmacoepidemiology. Guidelines for good pharmacoepidemiology practice (GPP). Pharmacoepidemiol Drug Saf. 2016 Jan; 25(1):2-10.
Effectiveness and Safety of Growth Hormone in Noonan Syndrome
Horm Res Paediatr 2020;93:380-395 